\title{
The Electrical Circuitry of an Olfactory Sensillum in Antheraea polyphemus ${ }^{1}$
}

\author{
J. J. DE KRAMER ${ }^{2}$
}

Mäx-Planck-Institut für Verhaltensphysiologie, 8131 Seewiesen, West Germany

\begin{abstract}
The aim of this study was to obtain a better insight into the distribution of active and passive electrical properties of the membranes of al olfactory sensillum. Such a sensillum is composed of three accessory cells which envelope the somata of two receptor neurons which have long $(300 \mu \mathrm{m})$ dendrites that are incorporated in cuticular protuberances (hairs). An electrical equivalent circuit of this organ is reconstructed which is based upon the response of sensilla to current transients, the shape of extracellularly recorded spikes, and the effects of lesions on these signals. A strong influence of membrane capacitances on the overall response and on the shape of spikes becomes apparent. From the combination of electrical and morphometric data it follows that the resistance of the apical membranes of the accessory cells in much higher than the resistance of their basolateral membranes. Neither in simultaneous tip and sidewall recordings nor in the hair (dendrite) amputation experiments could antidromic propagation of action potentials into the dendrite be demonstrated. The commonly accepted retrograde propagation explanation for the biphasic waveform of the spike is, therefore, rejected. Dendrite amputation experiments showed that the impedance of the dendrite does not limit the spike amplitude and that the dendrite contributes slightly to the duration of the positive phases of spikes. Both of these observations indicate that the dendrite is also involved in the generation of the leading phase of the spike. Consequently the proposition is made that action potentials are initiated at a dendritic location.
\end{abstract}

Insect sensilla are among the smallest multicellular sense organs and scem to be well suited for the study of functional cooperation between sensory neurons and accessory cells. In electrophysiological studies performed on sensilla (Morita, 1959, 1963; Morita and Yamashita, 1959; Wolbarsht, 1960; Thurm, 1963, 1970, 1974; Wolbarsht and Hanson, 1965; Rees, 1968; Yamada, 1971; Kaissling. 1971, 1979; Maes, 1976; Kaissling and Thorson, 1980; Guillet et al.,

Received December 4, 1984; Revised February 12, 1985

Accepted February 13, 1985

1 I wish to thank the Deutsche rorschungs gemeinschaft for financial support; Karl-Ernst Kaissling for his assistance with the experiments and discussion, Huky Kleindienst, Bob Pinter, Tom Keil, Ali Steinbrecht, Gloria Adamek, Chris Elliott, and Gaby Kahn for their critical comments on various drafts of the manuscript; and Leo Hoffmann, Hannes Sagunsky, and Ute Lauterfeld for their technical help.

${ }^{2}$ Present address: Abeiltung für Vergleichende Neurobiologie (Biologie IV) der Universität. Oberer Eselsberg M 25N, Postfach 4066, D-7900 Ulm, West Germany.
1980; Thurm and Küppers, 1980; Erlor and Thurm, 1981; Seyfarth et al., 1982; Fujishiro et al., 1984), the signal recorded by extracellular electrodes is usually considered to reflect the spatial distribuiton of various electrical events occurring at various sites of the plasma membrane of a sensory neuron taken to be located in a "volume conductor." Thus, bccause the leading phase of the spike ${ }^{3}$ is positive in such recordings, it was concluded that the action potential is initiated in or near the perikaryon of the sensory neuron, whereas the following negative undershoot was interpreted to be due to a retrograde propagation of the action potential into the dendrite.

Two cxcoptions to this "rule" were found by Seyfarth et al. (1982) and Erler and Thurm (1981). They described negative leading spike phases in some mechanoreceptors and proposed that in these special cases spikes were initiated in the dendrite.

The extracellularly recorded negative "receptor potential" is thought to be due to an inward current at the (dendritic) site of stimulus action. This signal is then conducted electrotonically (Rees, 1968; Kaissling and Thorson, 1980).

Results from many experiments, utilizing various chemical treat ments (e.g., topical application and presumed localized action of various anesthetics and tetrodotoxin, and modifications of the shape of spikes resulting from various types of stimulation) with various other types of sensilla were in agreement with this concept of the spatial organization of sensilla (Wolbarsht and Hanson, 1965; Morita and Yamashita, 1966; Yamada, 1971; Bernard and Guillet, 1972; Bornard and Pinet, 1973; Maes, 1976; Guillet et al., 1980; Erler and Thurm, 1981). There are at least two reasons to now reconsider these hypotheses concerning the organization of sensilla: (1) significant phase shifts or amplitude differences between spikes recorded simultaneously from the base (sidewall electrode) and the tip of an olfactory hair could not be demonstrated (de Kramer et al. 1984), and (2) the influence of intrinsic capacitances on the electrical behavior of the preparation has been largely ignored (Thurm, 1963; Rees, 1968; Bernard and Guillet, 1972). Attempts to include intrinsic capacitative elements in the functional analysis of sensilla were made by van Drongelen (1979), Stürckow (1971), de Kramer and van der Molen (1980), de Kramer et al. (1984), and Op de Beek et al. $(1980)$.

The olfactory sensilla on the antennae of the male silk moth Antheraea polyphemus (Fig. 1) (for morphological details, see Keil and Steinbrecht, 1983; Koil, 1984a, b; Stcinbrecht and Gnatzy, 1984) contain one to three (generally two) receptor neurons and three enveloping or accessory cells: the thecogen, the trichogen, and the tormogen cells. The hairs are about $300 \mu \mathrm{m}$ long, have only one lumen, and contain receptor lymph and the outer segments of the dendrites of the receptor neurons. These sensilla are especially suited to the analysis of the contribution of the dendrites to the overall behavior of the sensillum, as the hairs can be shortened,

\footnotetext{
${ }^{3}$ In this paper the term "spike" is used for the extracellular signal resulting from an intracellular action potential
} 
together with the dendrites, to different lengths without destroying the receptor function of the remaining portions (Kaissling, 1974).

\section{Materials and Methods}

Adult male moths of Antheraea polyphemus (Cramer), 1 to 4 days old, raised from pupae kindly supplied by $E$. Taschenberg (Fredonia, NY), were mounted on a glass rod with their antennae glued to a rubber base with Tangle trap (Tanglefoot Co., Grand Rapids, Ml). The reference electrode was inserted into the end of an antennal side branch from which the tip had been cut off. This electrode contained "hemolymph Ringer" (Kaissling and Thorson, 1980 ) and an $\mathrm{Ag}-\mathrm{AgCl}$ electrode of $1 \mathrm{~cm}^{2}$. In some experiments, isolated antennal side branches were fixed directly to the reference electrode. Conncction with the receptor lymph of a hair was made after severing the tip of the hair with a sharpened forceps covered with petroleum jelly (Kaissling, 1974). The Ag-AgCl recording electrode was filled with a $20 \%(\mathrm{w} /$ v) solution of polyvirylpyrrolidone $\left(M_{r}=360,000\right.$. Fluka $A$. G., Buchs, Switzerland) in "receptorlymph Ringer" (Kaissling and Thorson, 1980). Sidewall recordings (near the hair base) were made using the method of Morita and Yamashita (1959) by crushing the hair between two glass electrodes. Unless stated otherwise, the temperature of the air blown over the preparation during the experiments was $10 \pm 0.5^{\circ} \mathrm{C}$. The airstream velocity was $1 \mathrm{~m} /$ sec.

The electrical recording system consisted of a current clamping amplifier (de Kramer and van der Molen, 1979) which could be inserted in a simple feedback loop to establish voltage clamp recordings. Voltage clamp recordings were made using two electrodes only. Unless otherwise stated, the set current was zero in current clamp experiments; in voltage clamp recordings the set potential was normally equal to the standing potential of the preparation. Kootsley and Johnson (1972) buffer amplifiers with an input capacitance in the femtofarad range were also used in sume experinents. After amplification, the signals were low-pass filtered $(-3 \mathrm{~dB}$ at $10 \mathrm{kHz})$. The data were digitized and processed using a Nicolet Med 80 computer. To estimate time constants, the stored signals were oltset and their logarithms were

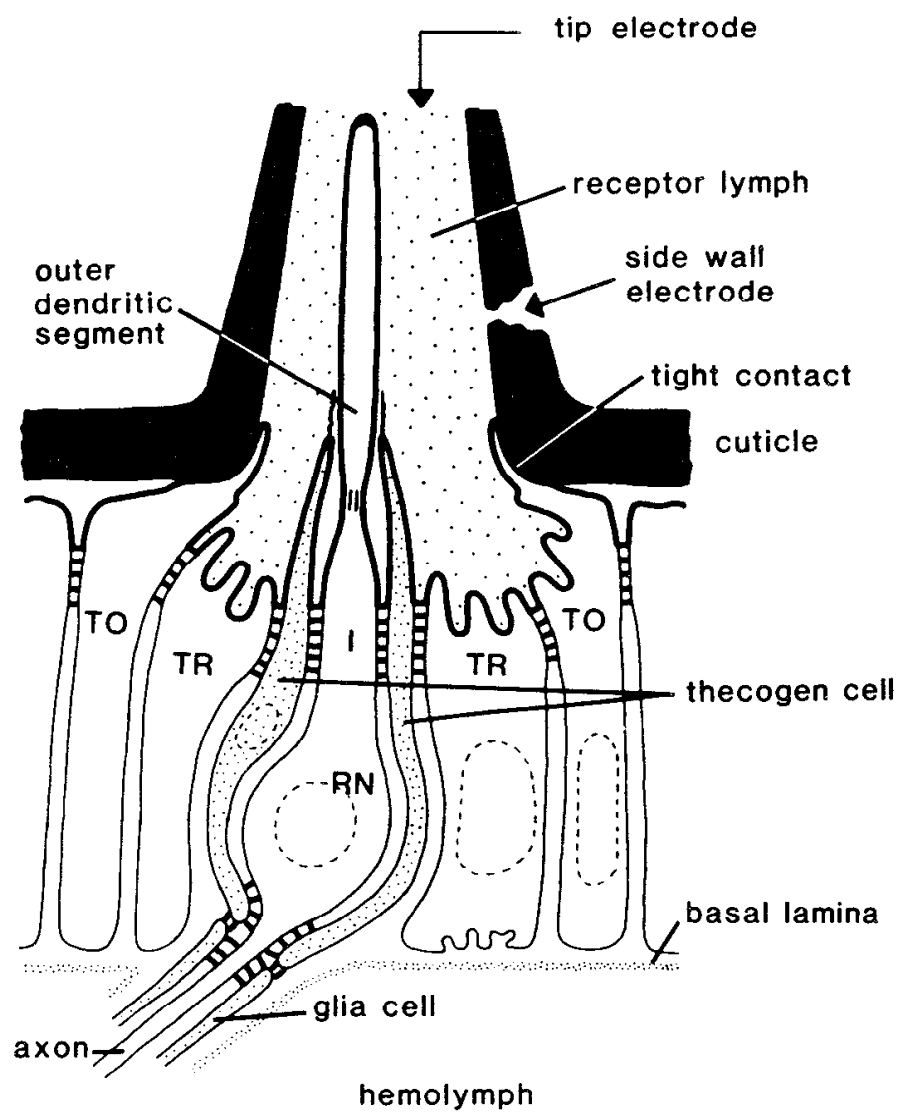

Figure 1. Caricature of a sensillum with severed tip and sealed dendrite. The apical membranes are drawn in bold lines, and the basolateral ones are drawn with thin lines. Modified after Keil (1984a) and Steinbrecht and Gnatzy (1984). I, inner dendritic segment; $R N$, receptor neuron; TO, tormogen cell; $T R$, trichogen cell.
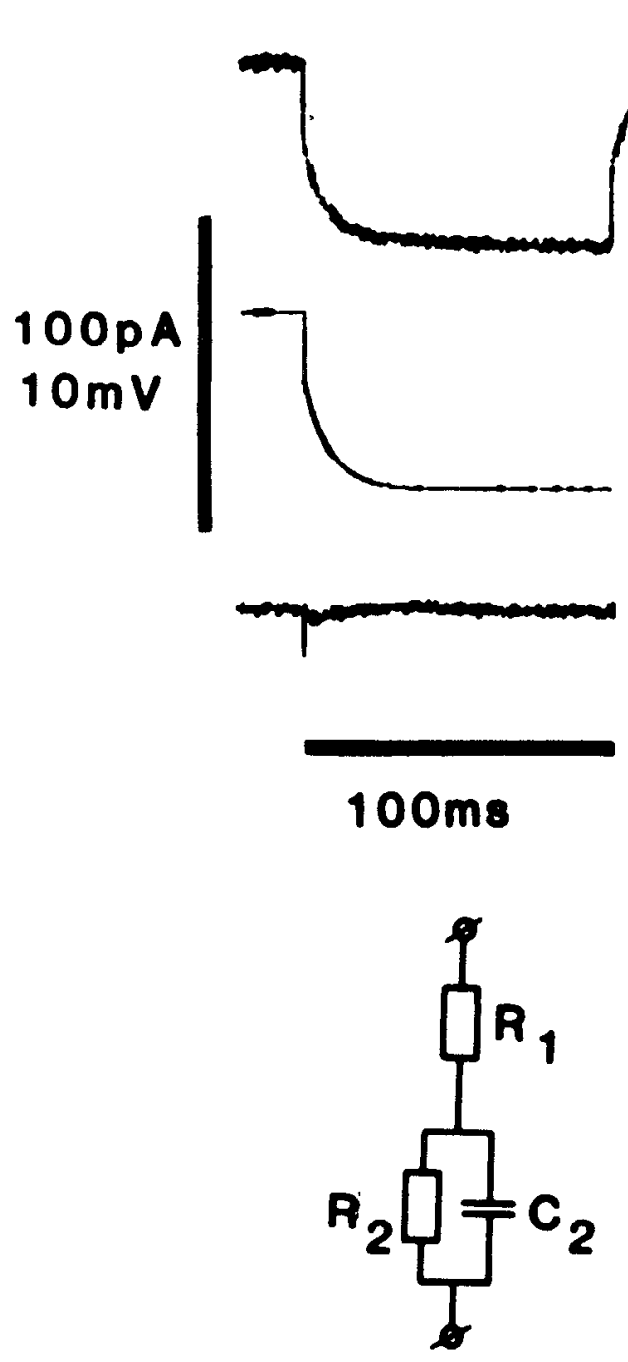

Figure 2. The response of a sensillum (trace $B$ ) to a $-50 \mathrm{p} A$ current pulso (trace $A$ ) of $100 \mathrm{msec}$ at $10^{\circ} \mathrm{C}$. The electrical equivalent $(E)$ largely mimics the response in $B$, as is shown in the simulation of trace $C$. In trace $D$ the signals from trace $B$ and the simulation $(C)$ are subtracted; only a small artifact remains.

taken. Through the logarithmized signal ( 5 to $20 \mathrm{msec}$ ), a regression line was drawn by eye and its slope was evaluated. In the suction experiment (see Fig. 7) suction was applied by a syringe connected to the reference electrode.

The measurement of $R_{1}$ in Figure 6 was performed by application of a sinusoidal current of $50 \mathrm{pA}$ peak to peak at a frequency of $200 \mathrm{~Hz}$ to the preparation. The response was analyzed in a transfer function analyzer (Feedback Ltd. model TFA 607). Here, the real component of the transfer function is shown.

Only the "large" amplitude spikes were analyzed. These spikes originate from the receptor neuron which is sensitive to the pheromone component $E_{6}, Z_{11}$-hexadecadienyl acetate (Kaissling, 1979).

\section{Results}

Response to current pulses and their temperature dependence. The dynamic response of a sensillum to square current pulses can be divided in two phases (de Kramer et al., 1984, Fig. 2): (i) a fast component $(F)$ with a time constant smaller tha $50 \mu \mathrm{sec}$, and (ii) a slow component $(S)$ with a time constant in the order of $10 \mathrm{msec}$ 


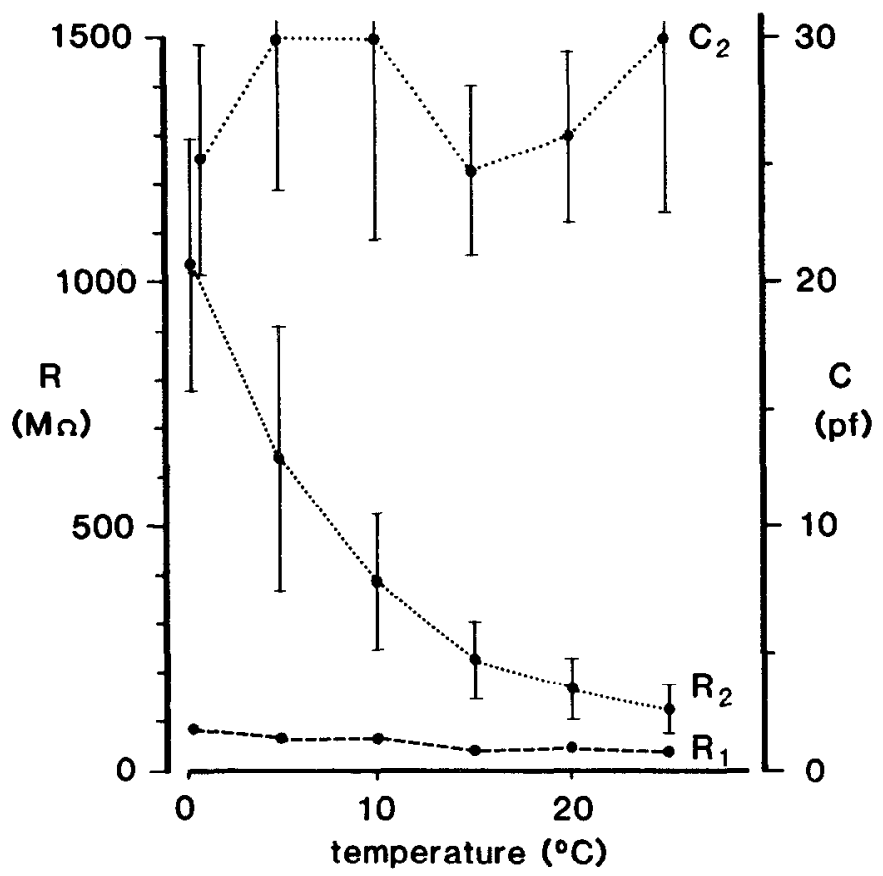

Figure 3. Averaged values of $R_{1}, R_{2}$, and $C_{2}$ of five sensilla as a function of the temperature of the air blown over the antenna (the standard deviation of $R_{1}$ is smaller than the dot diameters)

and an approximately single exponential behavior. This response to current pulses below $\pm 50 \mathrm{pA}$ is symmetric and linear. These findings may thus be ascribed to the passive electrical network of the preparation which is not just a resistive network but also contains capacitative elements.

The simplest equivalent scheme with such a behavior is that of Figure $2 E$. Here the fast component $(F)$ represents the currentinduced voltage drop over $R_{1}$ according to Ohm's law, whereas the slow component $(S)$ represents the steady-state (current-induced) voltage drop over $R_{2}$. From the time constant of the slow phase and $R_{2}$, the size of $C_{2}$ can be calculated

$$
\begin{aligned}
& R_{1}=\frac{F}{I} \\
& R_{2}=\frac{S}{I} \\
& C_{2}=\frac{\tau}{R_{2}}
\end{aligned}
$$

The value of $R_{1}$ includes the resistance of both recording electrodes, which is $12 \pm 2$ megohms at $20^{\circ} \mathrm{C}$ and $17 \pm 2$ megohms at $10^{\circ} \mathrm{C}$. The resistors of the circuit show a temperature dependence (Fig. 3); $R_{2}$ increases about 7 -fold when the temperature is decreased from $25^{\circ} \mathrm{C}$ to $0^{\circ} \mathrm{C}$, whereas $R_{1}$ doubles in the same range. The capacitance does not show a significant temperature dependence.

influences of lesions on the response of the sensillum. In order to be able to ascribe electrical properties of the sensillum to specific morphological elements, the effects of more or less defined structural alterations to the sensillum on the electrical transient response were studied. $R_{1}$ correlates well with the length of the hair, whereas no significant correlation between $R_{2}$ and $C_{2}$ and the hair length was found (Fig. 4).

$R_{1}$ may also be changed by alterations of the Ringer's solution within the recording electrode. When the solution was replaced by one containing Ringer diluted 1:10 but restored to its normal 450 mOsmol osmolarity (Kaissling and Thorson, 1980) by adding sucrose, the value of $R_{1}$ increased during several minutes, as shown in Figure 5, trace a. Afterwards, the recording electrode was replaced by one filled with the standard receptorlymph Ringer and, as a result, $R_{1}$ decreased toward a lower normal level (Fig. 5, trace $b$ ).

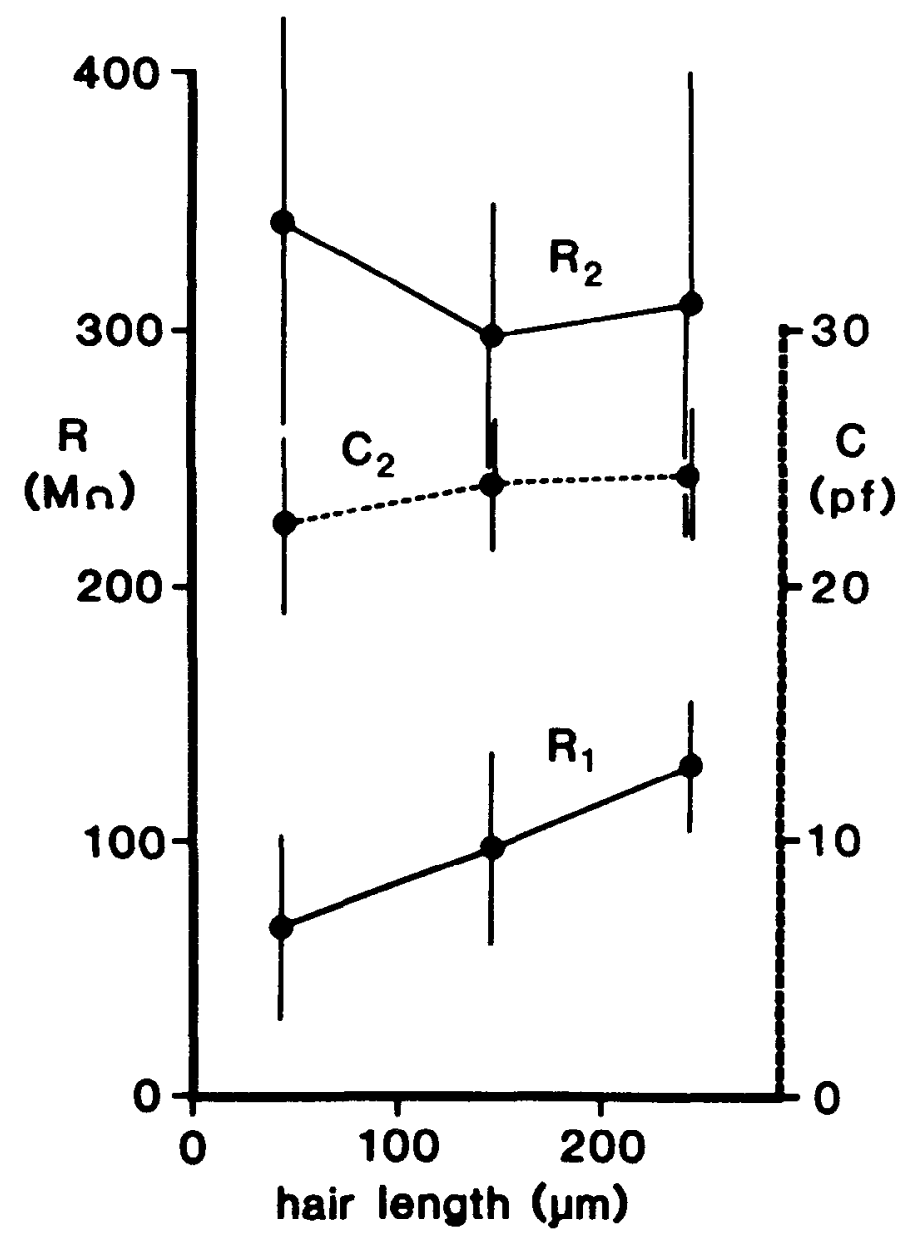

Figure 4. The correlation between the length of amputated hairs and the passive electrical properties. Values for $R_{1}, R_{2}$, and $C_{2}$ were determined from responses to current steps of $-50 \mathrm{pA}$. The $R_{1}$ values of long and short hairs are significantly different $\left(\rho<2 \cdot 10^{-4}\right)$.

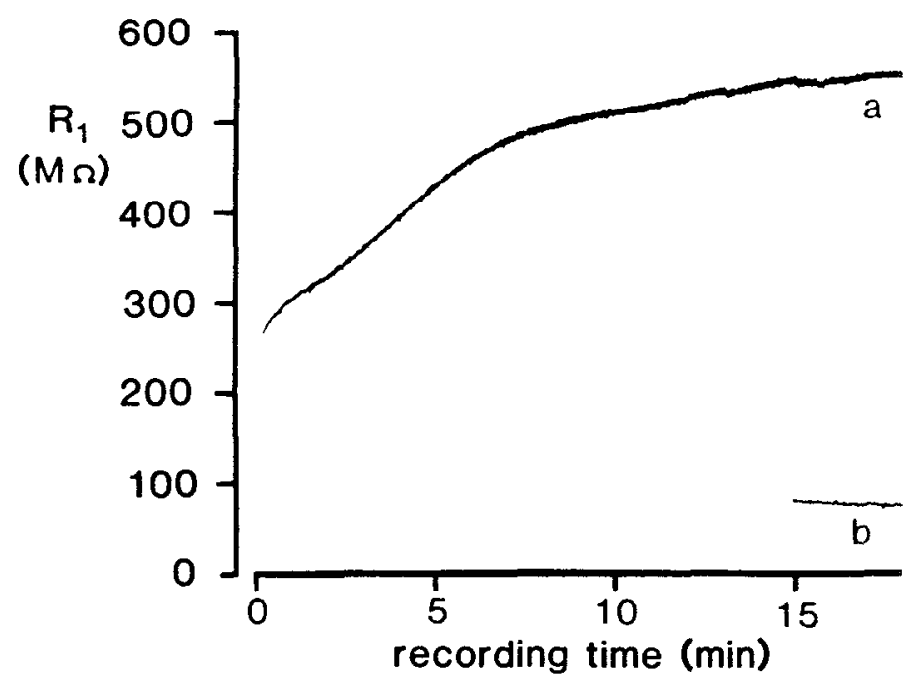

Figure 5. Trace a, An example of a change in $R_{1}$ when the recording electrode contains a 10 times diluted Ringer in which the osmolarity has been corrected by adding sucrose. Trace $b$, The value of $R_{1}$ of the same sensillum after subsequently recording for some time with the normal receptor Ringer. 


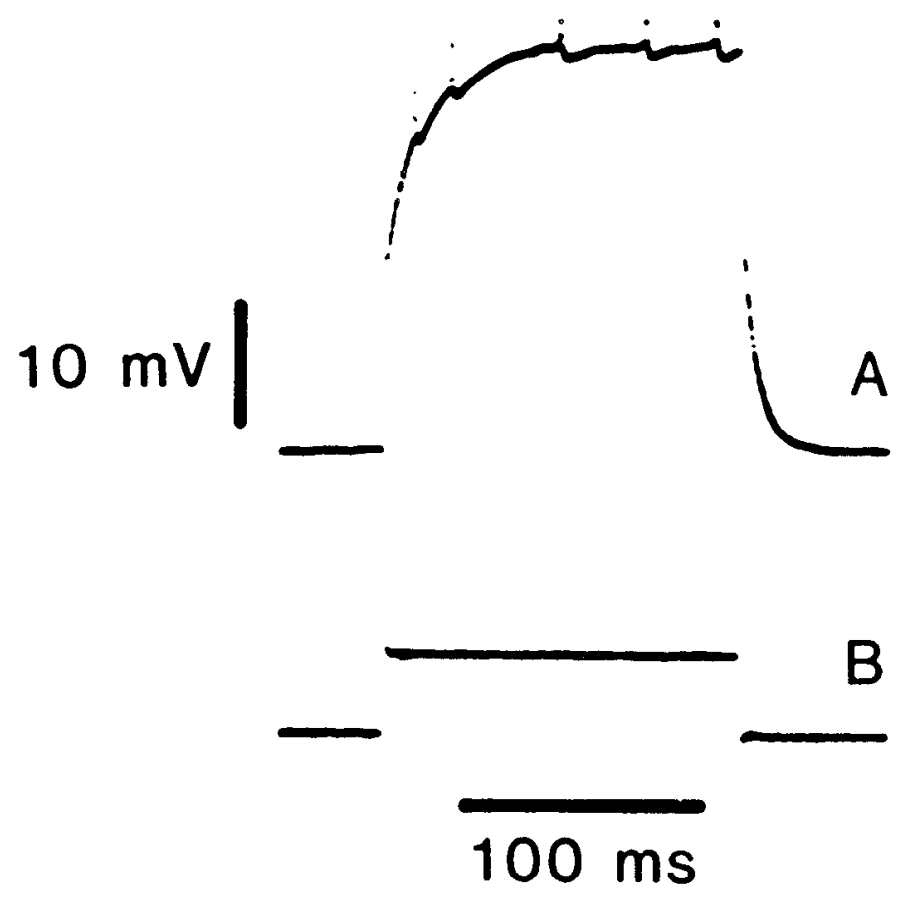

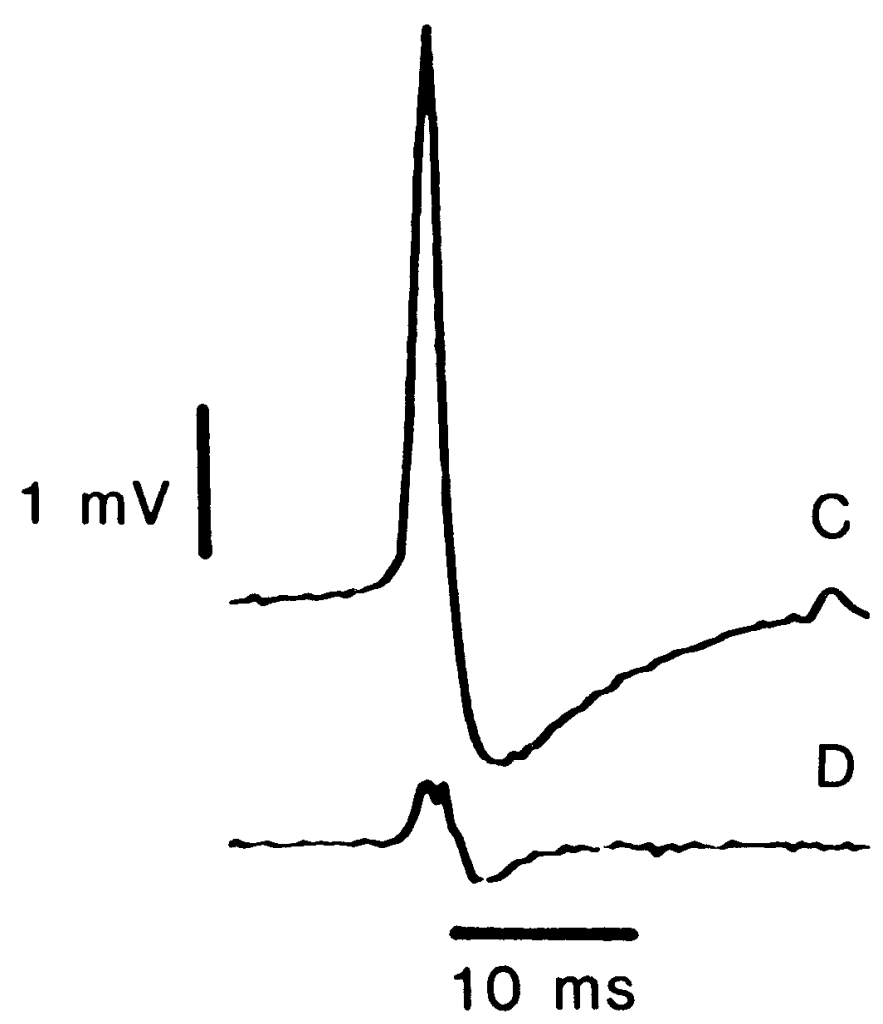

Figure 6. Effects of suction applied to the hemolymph space: the response of a sensillum to current injections before (trace $A$ ) and after suction (trace $B$ ) at $20^{\circ} \mathrm{C}$. Suction apparently destroys the $R_{2} C_{2}$ combination. Trace $C$, Records of spikes of the acetate receptor neuron elicited by a chemical stimulus before suction; $D$, after destruction of the $R_{2} C_{2}$ elements by suction. Averages of 25 spikes. (Courtesy of K. E. Kaissling).

When suction was applied to the epithelium via the reference electrode in the hemolyph space, a sudden irreversible breakdown of the standing potential would eventually occur. Such a breakdown was always accompanied by the disappearance of the slow component of the voltage response on current pulse injection, while the fast response remained (Fig. 6, traces $A$ and $B$ ). The ability of the reccptor neurons to produce spontaneous spikes or their ability to

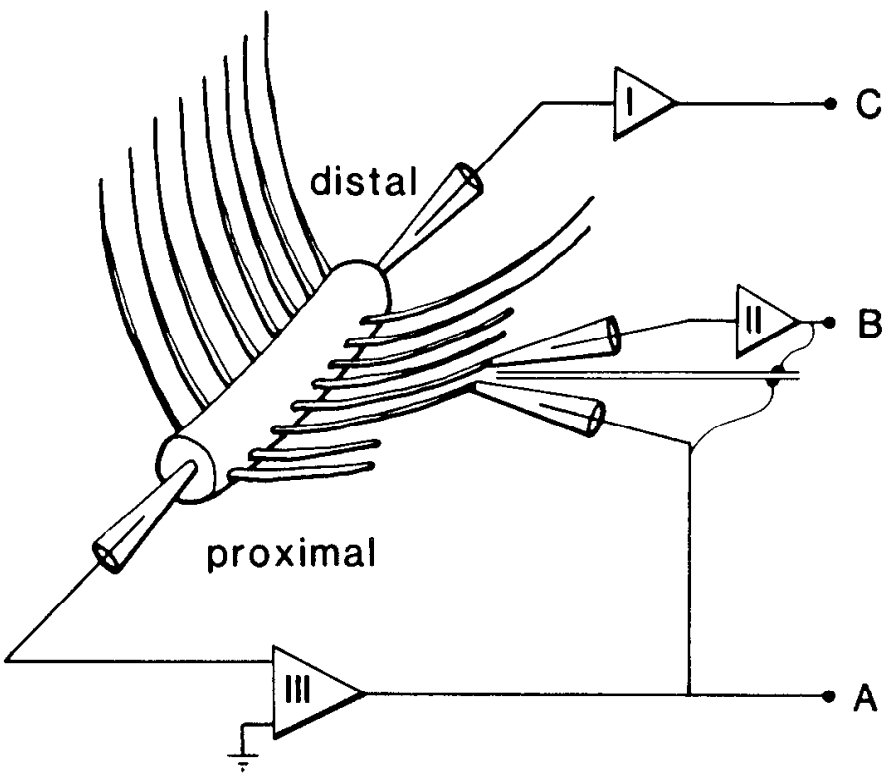

Figure 7. Set-up used to investigate the connections between neighboring sensilla. I and II, Kootsley and Johnson (1972) buffer amplifer. III. Current clamping amplifier. To prevent cross-talk between electrodes $A$ and $B$, a piece of double-plated circuit board was inserted between them with one side connected to the output of amplifer II and the other to the output of amplifier III.

respond to pheromone remain unimpaired. The recorded spikes are still biphasic but are smaller, and the decline of the negative phase is much faster (Fig. 6, traces $C$ and $D$ ). The most likely explanation for these findings is perforation of the epithelium below the hair under test. The neighboring sensilla are usually unaffected by this treatment (K. E. Kaissling, personal communication).

Electrical coupling between sensilla. In order to investigate whether $R_{2}$ and $C_{2}$ are located in one sensillum or are distributed in the antennal epithelium, the electrical coupling between sensilla was determined. Current steps were applied to one sensillum (Fig. 7A) and the voltage response to each current step was recorded from hair $A$ and an adjacent hair $B$. The third electrode $C$ was inserted in the hemolyph space to measure and later substract the artifacts produced by the impedance of the reference electrode and the hemolymph space. Figure 8 shows an example. Only a small and slow waveform can be recorded from the neighboring sensillum $B$. The absence of a fast phase suggests a coupling at the level between $R_{1}$ and the $R_{2}-C_{2}$ combination (Fig. 9). The value of the coupling resistance is apparent from the weak, slow component in the $B$ hair of Figure 8 and can be estimated from

$$
R_{C}=\frac{R_{2}}{R_{1}+R_{2}}\left\{R_{2}\left(\frac{V_{A}}{V_{B}}-1\right)-2 R_{1}\right\}
$$

where $V_{A}$ and $V_{B}$ are the steady-state amplitudes of the slow phases of neighboring sensilla. Between sensilla in the same longitudinal row, this resistance is about 2000 megohms; for sensilla in different rows the value is considerably higher.

The voltage dependence of the circuit elements. If current pulses larger than $50 \mathrm{pA}$ are applied to a sensillum, the response becomes nonlinear (Kaissling and Thorson, 1980). This nonlinearity appears in voltage clamp experiments when potentials larger than $+20 \mathrm{mV}$ are applied to the sensillum (Fig. 10). To investigate the source of the nonlinearity, current clamp experiments were performed in which brief current pulses were superimposed on a constant polarizing current (Fig. 11, $A$ and $B$ ). From the response to these pulses, $R_{1}$ and the time constant of the slow phase $\left(R_{2} \cdot C_{2}\right)$ were calculated. $R_{1}$ was found to be independent of the polarizing current, but the time constant increased significantly when positive current was applied (Figs. 11 and 12). 

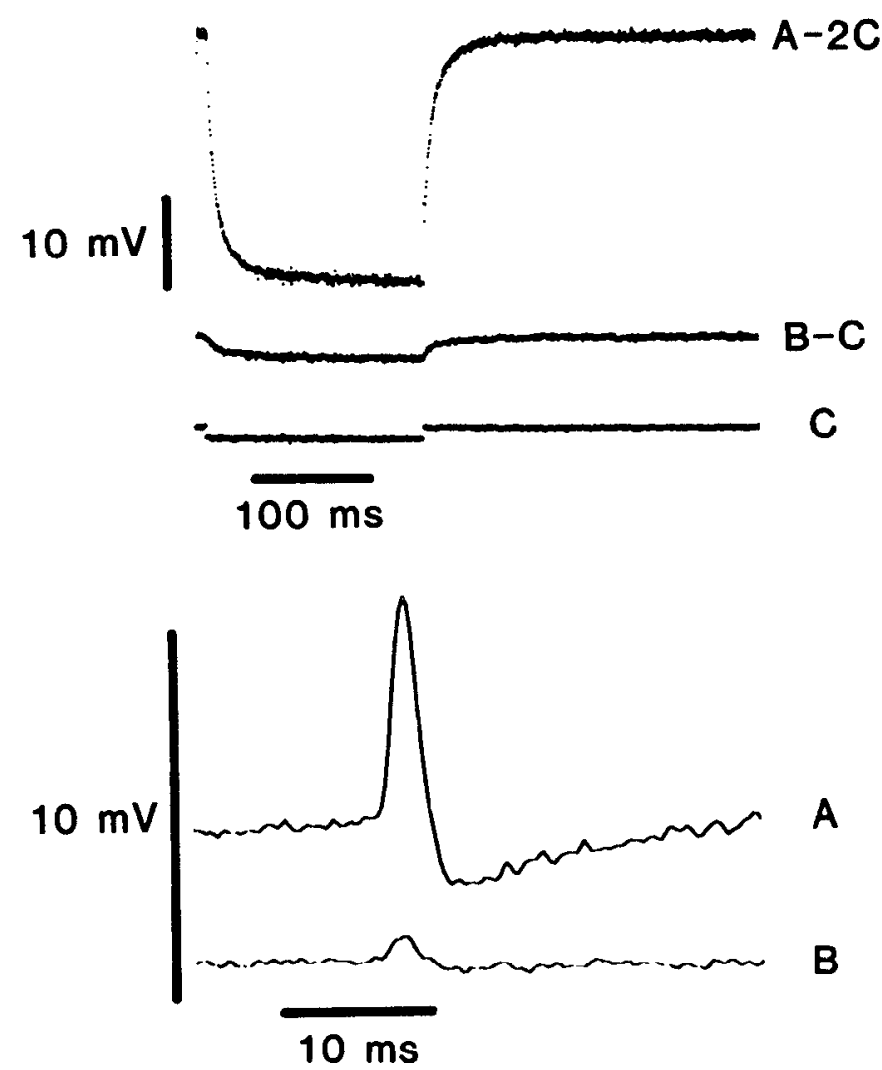

A

B

Figure 8. The result of an experiment as described in Figure 7. The upper throe traces show what happened when a current pulse of $-100 \mathrm{pA}$ was applied to sensillum $A$. From signal $A, 2 \times$ signal $C$ was subtracted to compensate for the two electrode impedances which influence the output at $A$. In signal $B$, only the arlifact due to the proximal electrode needs to be compensated. Only a small fraction of the potential across $A$ is fed through to sensillum $B$. Similar effects are seen with spikes (in the lower two traces). The spike recorded in $A$ triggered the averager. I he signal recorded simultaneously in $B$ displays a very much attenuated version of the spikes in sensillum $A$.

Correlates of the dynamics of the passive electrical network and the extracellular spike shape. In our preparation, spikes appear as biphasic events. In the recording set-up the leading phase $\left(p_{1}\right)$ is a positive voltage under current clamp conditions or negative current under voltage clamp. In current clamp experiments, the time constant of the spike recovery following the second peak (the "tail" of the spike) depends on the polarization potential of the preparation (Figs. 12 and 13). Temperature and polarizing current have a similar effect on the time constants of voltage transients and the tails of spikes (Fig. 13). The amplitudes of $p_{1}$ and $p_{2}$ phases of spikes (current clamp) are not very temperature dependent (Fig. 14).

When spike shapes were analyzed from voltage clamp recordings no influence of the polarization potential on the shape of the spike was observed (Fig. 12). When shapes of spike signals from current and voltage clamp experiments are compared, both spike phases appear to be much longer in current clamp recordings, which indicates an integrating or low-pass filtering effect of $R_{2}-C_{2}$ elements in the current clamp experiments (Fig. 15).

Effects of hair length. Recordings were made from hairs which were cut to different lengths (Fig. 15). The relation between $R_{1}$ and $R_{2}$ values, and the different lengths of these hairs, are shown in Figure 4. In current clamp experiments, amputation had little influence on the peak-to-peak amplitude of spikes. Careful investigation revaled that amputated hairs had a somewhat shortened positive phase and a significantly larger negative amplitude (Fig. 16A). In voltage clamp experiments, both the $p_{1}$ and $p_{2}$ amplitudes of the spikes increased alter shortening of the hair (Fig. 16B).

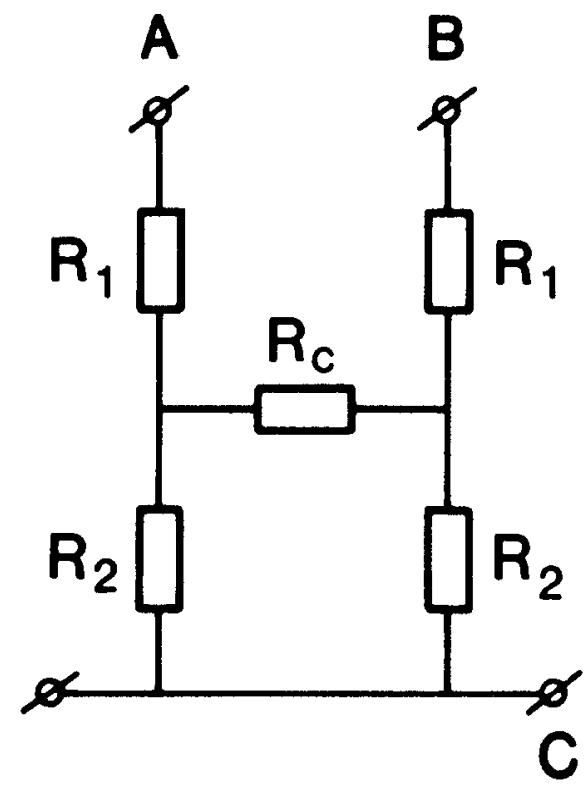

Figure 9. Circuit used for the interpretation of the coupling resistance $Z_{c}$ between neighboring sensilla as described in Figs. 7 and 8 . The response at $B$ shows only the "slow" phase, and as all of the readings were taken after the steady state of the responses had been reached, no capacitors need to be taken into consideration.

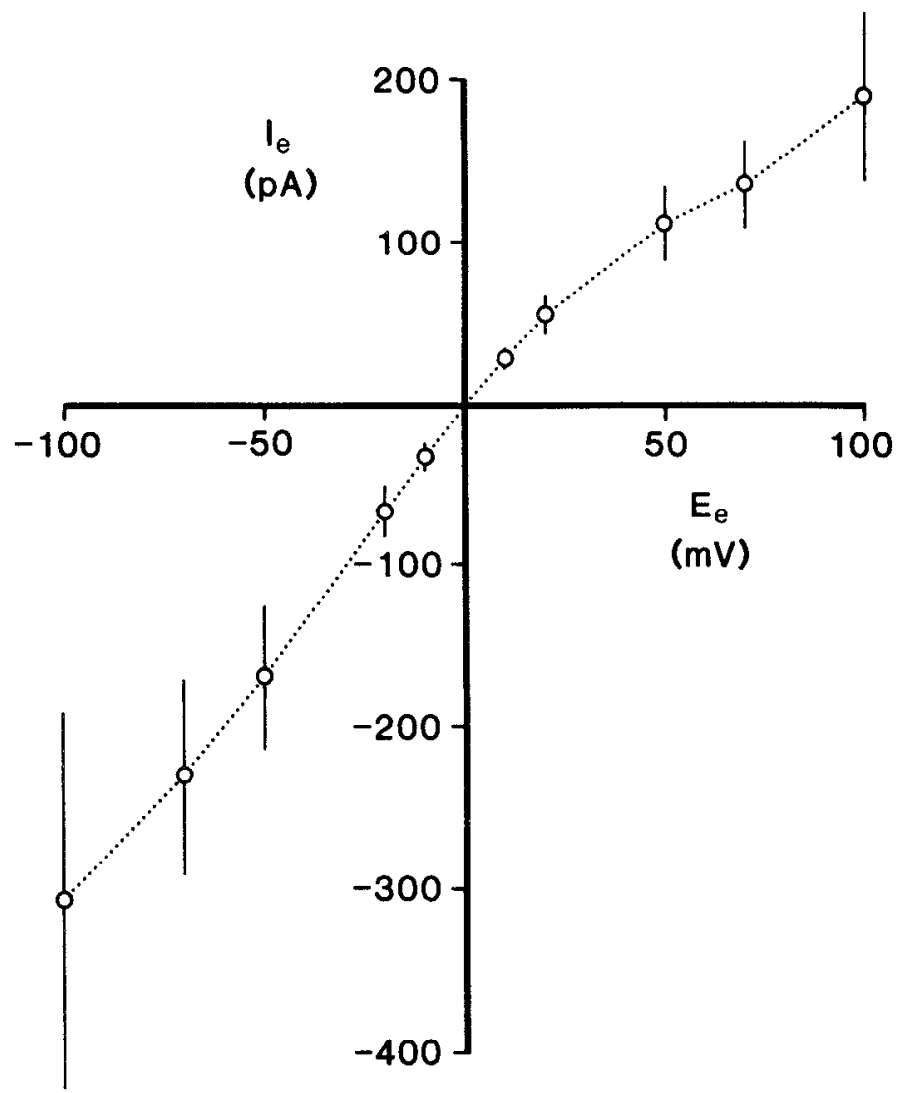

Figure 10. Averaged steady-state amplitudes and standard deviations from four voltage clamp experiments. Zero voltage corresponds to the standing potential between hair tip and hemolymph.

\section{Discussion}

The response of the sensillum to applied current pulses can be described in terms of a very simple network (Fig. 2). This is partly due to the relative insensitivity of the current pulse method to detect multiple time constants (Jack et al., 1975; Clausen et al., 1983). The 

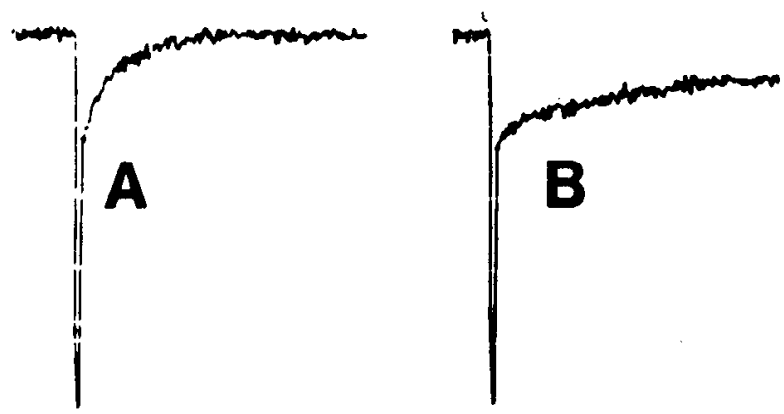

$-40 m V$

$+80 \mathrm{mV}$
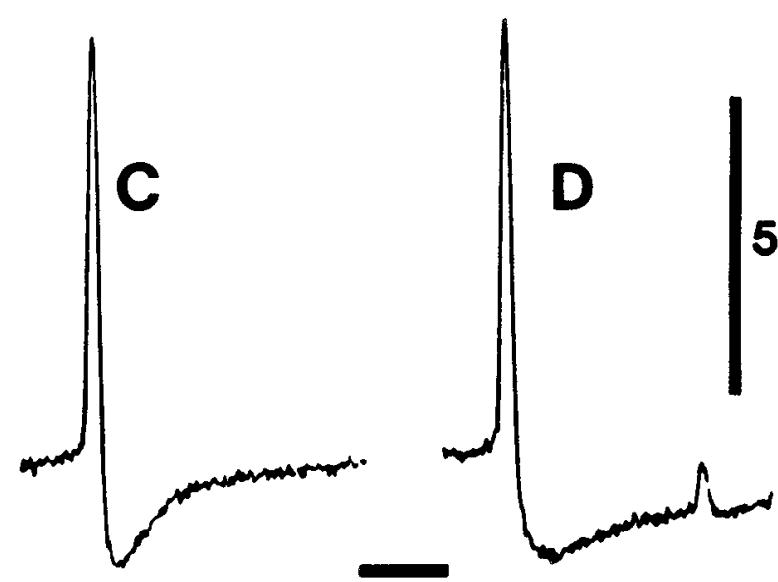

$10 \mathrm{~ms}$

Figure 11. Upper traces, The response of sensilla to brief (1 msec) current pulses of $-50 \mathrm{pA}$ at $10^{\circ} \mathrm{C}$ in current clamp configuration. A: At a polarization potential across the sensillum of $-40 \mathrm{mV} ; B$ : with a polarization potential of $+80 \mathrm{mV}$. Note the prolonged time constant of the "tail." Lower traces, Spontaneous spike potentials. $C_{\text {; }}$ At a polarization potential across the sensillum of $-40 \mathrm{mV} ; D$ : at a polarization potential of $+80 \mathrm{mV}$. Note that, also, with spike potentials the time constant of the "tail" is longer with positive potentials across the sensillum.

electrical stabitity of an olfactory sensillum, however, is not sufficient to directly exploit strategies with a larger resolving power (e.g., transfer function). The linearity of the response suggests that the dynamics of the current pulse-induced behavior is the result of passive electrical properties of the preparation rather than of active electrical processes.

The resistive component $R_{1} . R_{1}$-as determined from the fast transient of the voltage response to an applied current step-can be divided into a portion related to the length of the hair $\left(R_{h}\right)$, a contribution of about 17 megohms from the electrode resistance, and a residual resistance $\left(R_{r}\right)$ of 10 to 40 megohms which largely represents the resistance of the piece of antenna between the reference electrode and the sensillum under test $(\mathrm{J}$. J. de Kramer, unpublished observation). The values found for $R_{1}$ correspond to computed resistances of morphometrically analyzed hair lumina (Keil, 1984a) when filled with an electrolyte of a specific resistance of $50 \mathrm{ohm} \cdot \mathrm{cm}$ at $10^{\circ} \mathrm{C}$ (Kaissling and Thorson, 1980). Figure 5 shows that the hair lumen adopts the electrolyte conductivity of the recording electrode within a few minutes. Therefore, the value which is normally obtained for $R_{1}$ will not represent its real physiological value.

The $R_{2}-C_{2}$ complex. The parallel elements $R_{2}$ and $C_{2}$ show no significant correlation with the length of the hair (Fig. 4) and must therefore be mainly located in the epithelium below the hair. Moreover, the lack of an appreciable electrical coupling between sensilla (Fig. 10), which is probably due to the tight contact between the

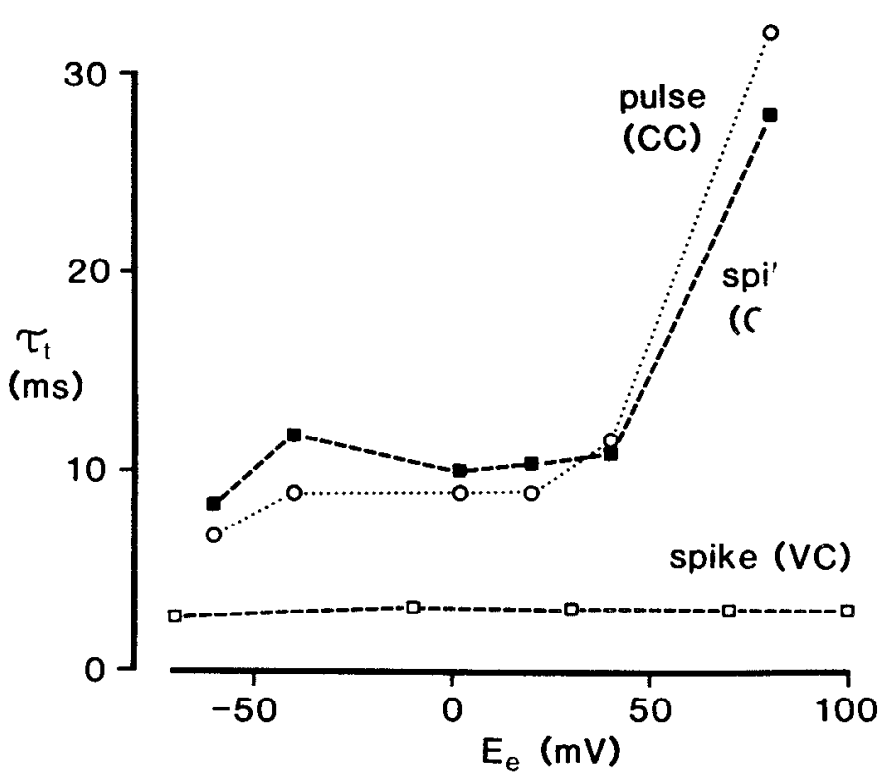

Figure 12. The time constant of tails of spikes and responses to brief current pulses of one sensillum. Under current clamp (CC) conditions the relationship between time constant and steady potential across the sensillum is similar for current pulse responses and spike potentials; under voltage clamp (VC) conditions the time constant of the tail of a spike is not dependent on the polential acruss the serisillurin. Zero voltage corresponds with the standing potential between hair tip and hemolymph.

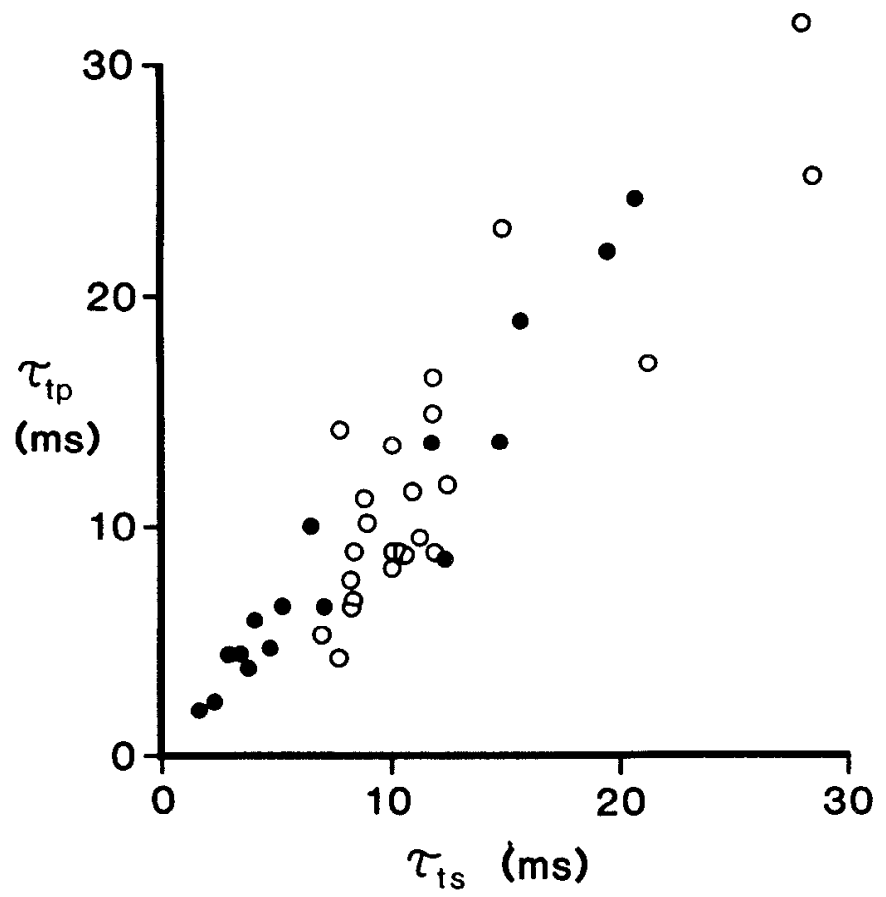

Figure 13. Time constants of tails of spikes $\left(\tau_{\mathrm{ts}}\right)$ versus time constants of responses to $1-\mathrm{msec}$ pulses $\left(\tau_{\mathrm{tp}}\right) . \mathrm{O}$, at $10^{\circ} \mathrm{C}$ under various polarizing currents; - , without polaricing current al ternperatures between 0 and $25^{\circ} \mathrm{C}$.

tormogen cells and the cuticle (Keil, 1984b), signifies that $R_{2}$ and $C_{2}$ should be largely attributed to the cells of one sensillum. Between the receptor lymph space and the hemolymph space, two layers of membranes are possible locations for $Z_{2}$ (= the $R_{2} C_{2}$ combination): the apical and, not mutually exclusive, the basal and lateral membranes of the sensillar cells. Thus, from the morphology one should expect a decay of the slow component according to (see Fig. 17A)

$$
V=I\left(R \cdot e^{-t / R_{a} \cdot c_{a}}+R \cdot e^{-t / R_{b} \cdot c_{b}}\right)
$$




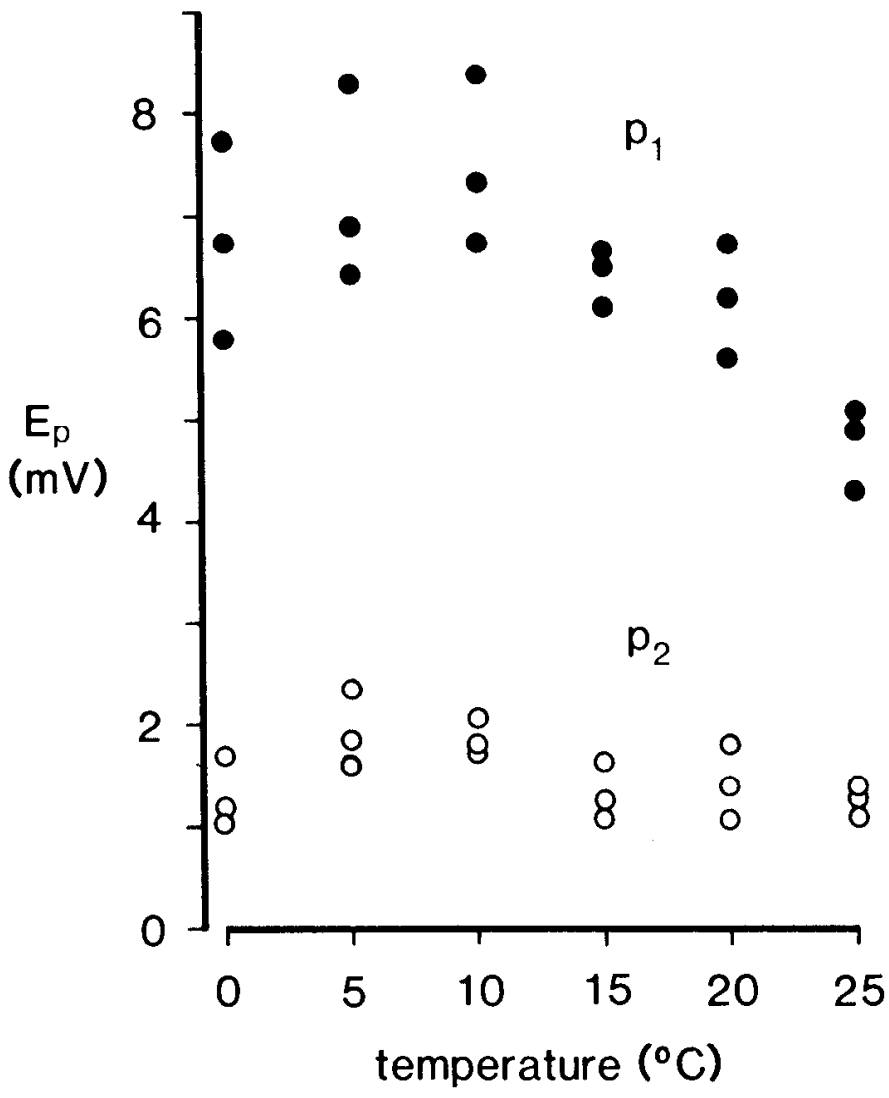

Figure 14. Amplitudes of spontaneous spikes in current clamp measurements at various temperatures. $P_{1}$, the amplitude of the leading positive phase; $P_{2}$, the amplitude of the second, negative phase.

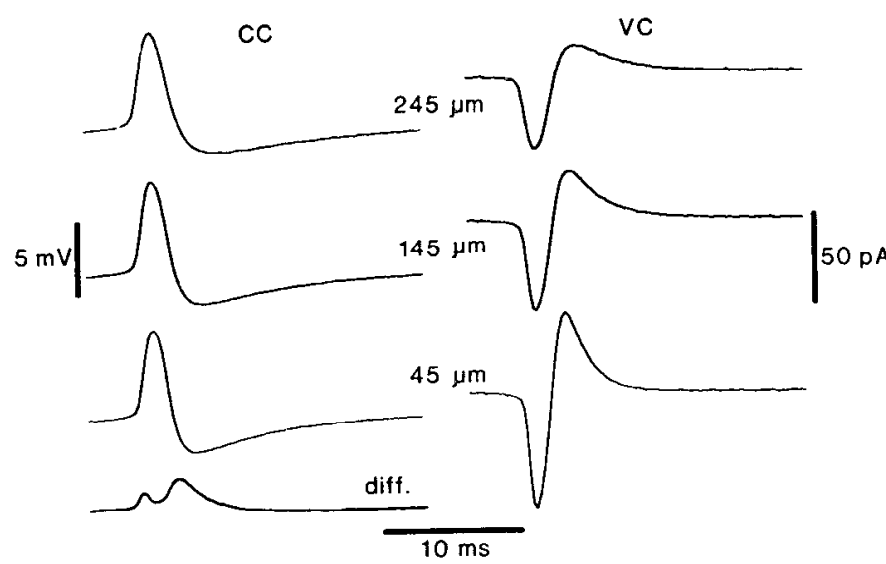

Figure 15. Spontaneous nerve impulses, as recorded under current (CC) and voltage clamp (VC) conditions from cut-off hairs. Averages of 11 sensilla at each hair length (10 impulses/hair) are shown. The diff. trace represents the differcnce between the current clamp signals recorded from the $215-\mu \mathrm{m}$ sensilla and those from the $45-\mu \mathrm{m}$ ones.

Noise, inherent in measurements, prohibits the calculation of the unknown parameters in this equation from the experimentally acquired waveform and amplitude of the slow phase alone (cf. Acton, 1970). To overcome this difficulty, parameter values for the capacitances in the network in Figure $17 \mathrm{~A}$ were derived from morphometric data of a relaled species, Antheraea pernyi (Gnatzy et al., 1984). A specific capacitance of $1 \mu \mathrm{f} / \mathrm{cm}^{2}$ was taken for these membranes (Cole, 1972). Because the summated apical membrane area of one sensillum is about $3000 \mu \mathrm{m}^{2}$, and as the basolateral membrane area is about $1800 \mu \mathrm{m}^{2}$, a value of $30 \mathrm{pf}$ can be assigned to $C_{a}$ and $C_{b}$, respectively. As $R_{2}$ represents the DC resistance of the epithelial
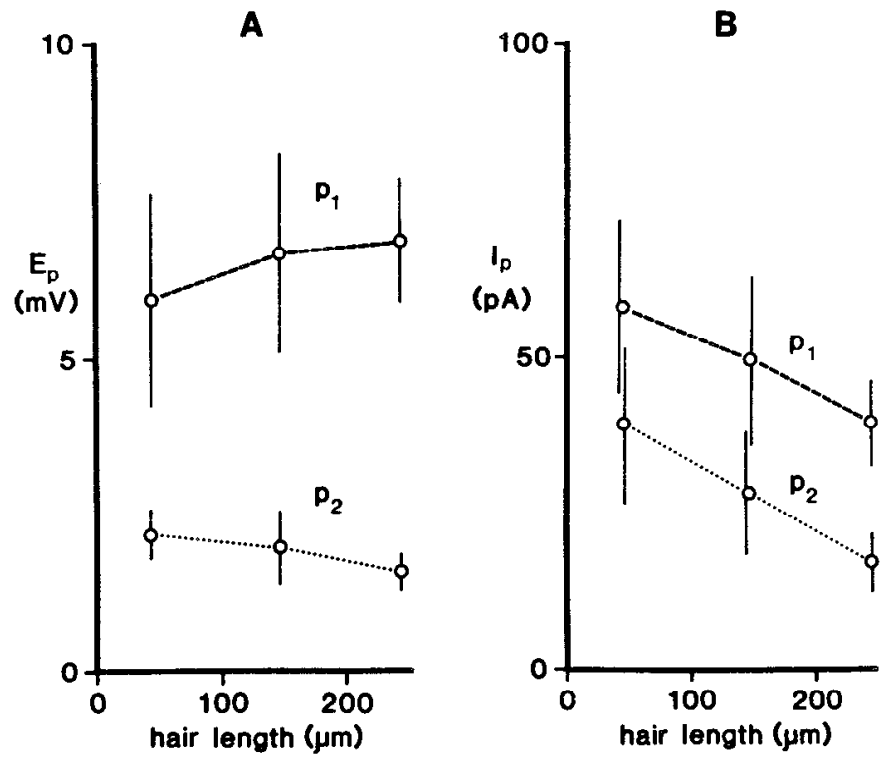

Figure 16. The correlations between the length of amputated hairs and spike amplitudes of the same group of hairs as in Figures 4 and 15. A, Positive $\left(\rho_{1}\right)$ and negative $\left(\rho_{2}\right)$ peak spike amplitudes in current clamp configuration. Only the $p_{2}$ phases from large and small hairs are significantly different $\left(\rho<5 \cdot 10^{-4}\right)$. B, Peak spike currents of first $\left(\rho_{1}\right)$ and second $\left(p_{2}\right)$ spike phases in voltage clamp configuration. The differences between long and short hairs are significant $\left(p<2 \cdot 10^{-4}\right)$.

A

B

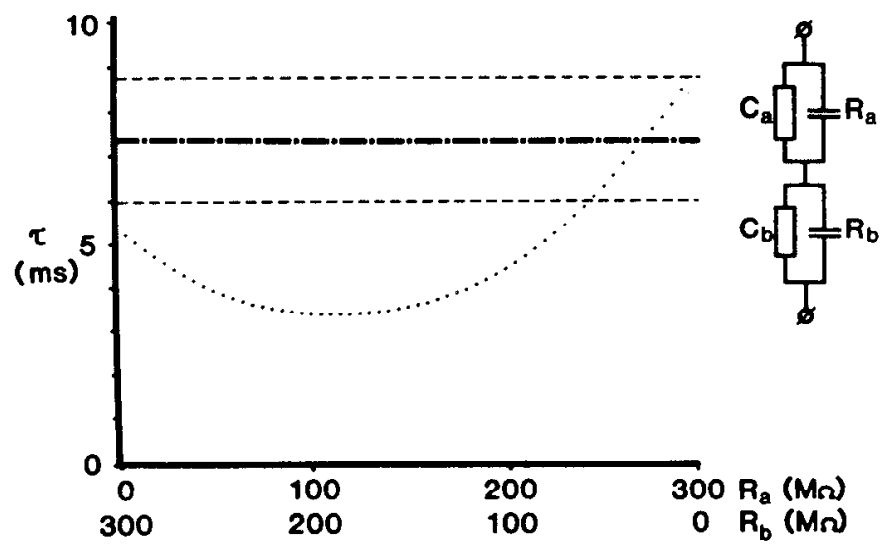

Figurc 17. $A$, The circuit used in the simulations in which the relative contributions of the apical and basolateral membranes of the supporting cells to the overall response of the sensillum were estimated. $B$. The "overall" tirme constant $(\tau)$ of the circuit of $A$ with $C_{a}$ and $C_{b}$ fixed at values of 30 and $18 \mathrm{pf}$ at various partitions of $R_{2}$ (300 megohms) over $R_{\mathrm{a}}$ and $R_{\mathrm{b}}$. Note that the resulting (dotted) curve has only intersections with the time constant tound in experiments (mean dashed-dotted line \pm standard deviations, dashed lines) when $R_{a}$ is larger than 10 .

part of one sensillum, this value can be taken for the sum of $R_{a}$ and $R_{b}$. In simulation experiments the overall time constant of the network of Figure $17 \mathrm{~A}$ was estimated after various partitions of $R_{2}$ between $R_{a}$ and $R_{b}$. The result of this simulation (Fig. 17B) is that the experimentally derived time constant of the preparation is reached when the resistance ratio $R_{a} / R_{b}$ is about 10 or larger. This implies that the specific resistances of the apical and basolateral membranes are very different, about $9000 \mathrm{ohm} \cdot \mathrm{cm}^{2}$ and $500 \mathrm{ohm} \cdot \mathrm{cm}^{2}$, respectively. The accuracy of these estimates is mainly limited by the morphometric data of Gnatzy et al. (1984), who estimate a possible error of $\pm 25 \%$. Note that the difference in membrane resistances on the two sides of the epithelium is much greater than most previously published values (see Clausen and Wills, 1981). 


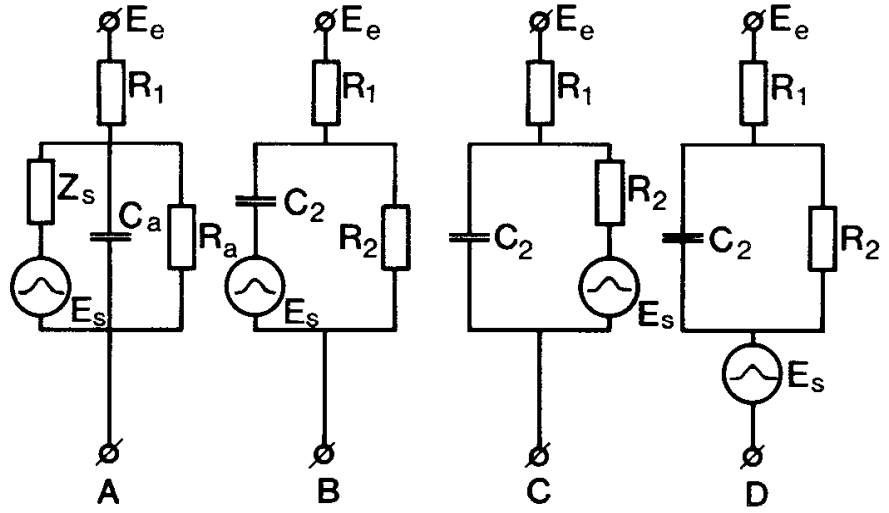

Figure 18. Four alternative equivalent networks of the preparation in which all display a current transient response similar to those of Figure 2 and in which "spikes" $\left(E_{s}\right)$ show an influence of voltage or current clamp configurations similar to those of spikes from the sensillum (Fig. 15). $E_{s}$ stands for the action potential generator complex; in $A, Z_{s} / / C_{a} / / R_{a} \approx R_{2} C_{2}$.
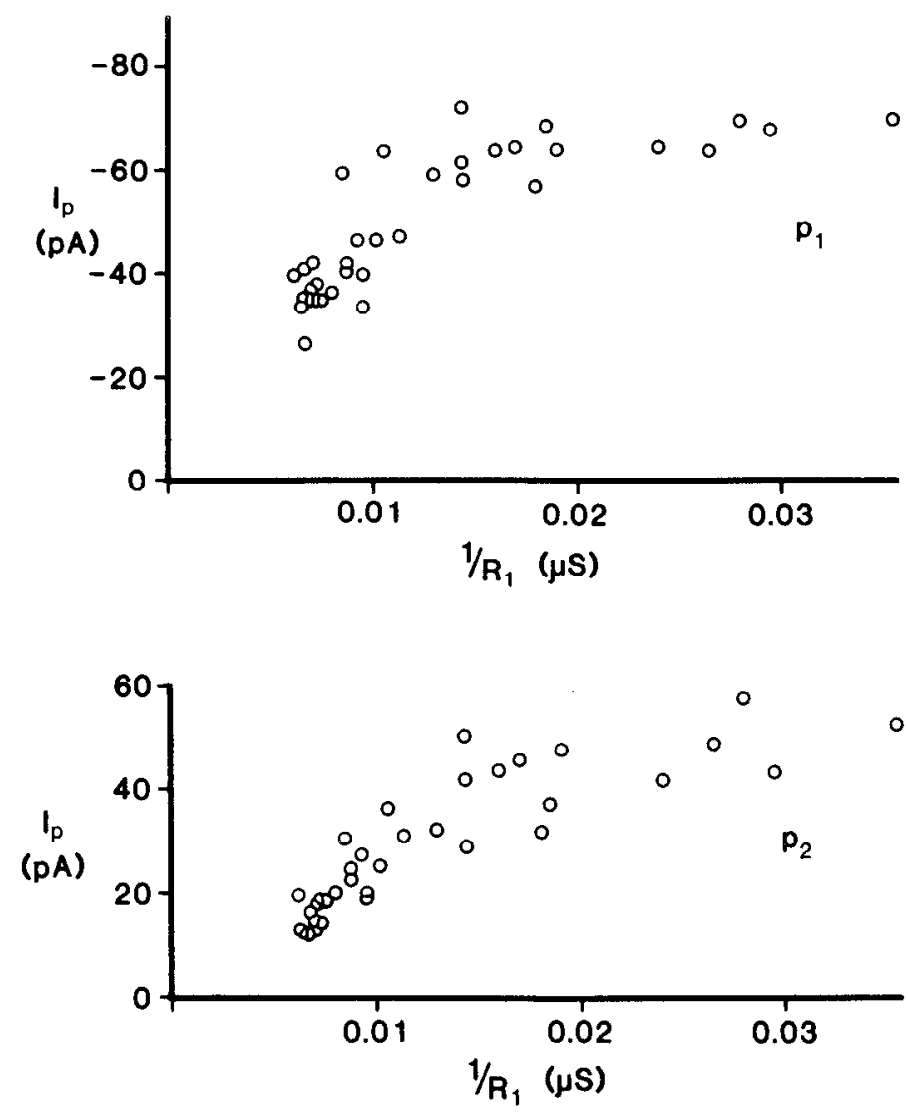

Figure 19. Peak spike currents (from Fig. 16B) plotted versus the reciprocal $R_{1}$ values (from Fig. 14A) of each of the hairs. Note the saturation the peak spike current at larger values of $1 / R_{1}$.

In the region of the apical membranes of the accessory cells, the following structures may contribute to $R_{2}$ : the interceilular clefts, the apical membranes of the accessory cells, and the sensory neurons. The electrically parallel arrangement of these components allows only the calculation of a lower limit for their individual resistivities.

a. For the apical membranes of the accessory cells a resistivity of $300 \mathrm{megohms} / 2200 \mu \mathrm{m}^{2}$ or $6.6 \mathrm{kilohm} \cdot \mathrm{cm}^{2}$ was calculated.

$b$. The intercellular clefts (with septate junctions) of one sensillum have a length of about $50 \mu \mathrm{m}$ and an average depth of $2 \mu \mathrm{m}$; their width is approximately $10 \mathrm{~nm}$. To obtain the 300-megohm value of $R_{2}$, a resistivity of $7500 \mathrm{ohm} \cdot \mathrm{cm}$ of the intercellular elements is required. Note that this lower limit is considerably higher than the specific resistivity of receptor and hemolymph $(50 \mathrm{ohm} \cdot \mathrm{cm})$. This demonstrates the extraordinary isolating efficacy of septate junctions (Loewenstein and Kanno, 1964).

c. The surface area of the small plus the large dendrite is $430+$ $221 \mu \mathrm{m}^{2}$ (Keil, 1984a). Thus, the minimum resistivity of the apical membranes of the receptor neurons would be $1950 \mathrm{ohm} \cdot \mathrm{cm}^{2}$.

The temperature dependence of $R_{1}$ and $R_{2}$. The data of Figure 3 allow an estimation of a $\mathrm{Q}_{10}$ of 1.5 for $R_{1}$ and a $Q_{10}$ of 2.5 for $R_{2}$. The $Q_{10}$ of $R_{1}$ is similar to that of a $200 \mathrm{mM} \mathrm{KCl}$ solution (Rauen, 1964), which is to be expected since receptorlymph Ringer is largely $\mathrm{KCl}$. The $\mathrm{Q}_{10}$ of $R_{2}$ is within ranges found in membrane resistances (Murray, 1966). This result is consistent with the abovementioned interpretation of $R_{1}$ and $R_{2}$.

The electrical excitability of the $R_{2}$ element. $R_{1}$ is not voltage dependent as the fast response to current pulses does not show any voltage dependence. The nonlinear E-I curve of Figure 10 (Kaissling and Thorson, 1980) is presumably the result of a voltage dependence of $R_{2}$, as the voltage dependence of the time constant in current clamp experiments (Figs. 11 to 13) can be explained only by a voltage dependence of $R_{2}$. A considerable voltage-dependent membrane capacitance change is very unlikely (Cole, 1972).

The relationship between the waveform of a spike and the electrical network of a sensillum. In disagreement with Morita and Yamashita (1959) and Wolbarsht and Hanson (1965), no significant phase and amplitude difference between tip and sidewall recorded spikes could be demonstrated in olfactory sensilla of Antheraea polyphemus (de Kramer et al., 1984). Causes for this important discrepancy may be the more tangeled morphology of taste hairs (which have two lumina), or electrode capacitances. Electrode capacitances, or their compensation, may seriously affect the waveshapes of spikes. However, neither Morita and Yamashita (1959) nor Wolbarsht and Hanson (1965) mention any precaution they took to prevent this. In this study, such artifacts were largely averted by working at low temperatures and by the application of intrinsically low input capacitance buffer amplifiers. The absence of significant temporal or amplitude differences between tip and sidewall recorded signals means that retrograde propagation of action potentials can no longer be used to explain the waveform of spikes; other mechanisms must be held responsible.

Two results suggest that the shape of spikes is influenced by the previously described passive network elements of the preparation. First, the time constant of the tail of the spike depends upon polarization and temperature exactly as the $R_{2} C_{2}$ time constant does (Figs. 11 to 13). Second, when spikes are recorded from short hairs in current clamp experiments, their duration is considerably longer than that of spikes in voltage clamp experiments (Fig. 15). These observations can be explained using the circuits of Figure 18 as equivalent networks of the preparation. The circuits $B, C$, and $D$ of Figure 18 can be ruled out as they require rather odd boundary conditions to fit the data on the amplitude of recorded spikes at various temperatures (Fig. 14); the amplitude of (intracellular) action potentials is probably just slightly temperature dependent (Abrams and Pearson, 1982). The circuit of Figure $18 \mathrm{~A}$ does not require strict boundary conditions and is the most likely equivalent network. Also, the effect of an epithelial perforation on the shape of the spike (Fig. 6) signifies a parallel arrangement of the action potential generator complex and the larger part of $Z_{2}$. Compared to Figure $2 E$, the equivalent circuit of Figure $18 \mathrm{~A}$ has two extra elements: $Z_{\mathbf{s}}$ and $E_{s}$. The parallel combination $Z_{s}-C_{a}-R_{a}$ equals the earlier descriptive $R_{2}-C_{2}$ combination. The new side branch with $E_{s}$ and $Z_{s}$ probably represents a transepithelial current pathway through the receptor neuron. The equivalent network of Figure $18 \mathrm{~A}$ is qualitatively similar to those described by Thurm (1963, 1970, 1974), Thurm and Küppers (1980), Kaissling and Thorson (1980), and Rees (1968). Constituent elements of $Z_{s}$ are not necessarily restricted to elements of the sensory neuron. Electron microscopic investigations (Keil and Steinbrecht, 1983) revealed that apically and basally arranged septate junctions isolate the intercellular spaces between the receptor 
neurons and the thecogen cell from both the receptor- and the hemolymph spaces. These findings indicate that $Z_{s}$ must consist of a combination of neuron and thecogen elements and that the two remaining accessory cells account for the $R_{a}-C_{a}$ combination.

The current pulse response network analysis applied in the first part of this paper cannot distinguish $Z_{s}$ from $R_{a}-C_{a}$. Analysis of the amplitude and waveform of "spontaneous" spikes provides an alternative method to investigate the electrical properties of $Z_{s}$ (and $E_{s}$ ). The information thus gained is rather limited, as nothing is known about which membrane(s) generate(s) action potentials, or about their transmembranous time course. Moreover, not all elements of 7. will be linear or constant, especially not during spikes.

When the current clamp spike signal from a short hair is subtracted from the signal of a long hair, a largely positive event remains (Fig. 15). This may indicate that the dendrite contributes mainly to the positive phase of spikes. This disagrees with the model of Thurm and Küppers (1980), who propose that electrical activity of the dendrite contributes to the negative phase of the spike only. This proposal is based upon the assumption that the shape of extracellularly recorded spikes gives a reliable indication of the course of ionic currents, which is not always the case (Elliott, 1983). In fact, simultaneous intra- and extracellularly recorded signals often give contradictory information about the time course of ionic currents as can be seen in recordings by Freygang and Frank (1959), Terzulo and Araki (1961), Grace and Bunney (1983), Katz and Miledi (1965), and Tomita (1956).

Freygang and Frank (1959) proposed that differentiation of the intracellular signal by the capacitance of the membrane beneath the extracellular electrode was responsible for this effect. Following this logic, a reduction in the surface area of the dendritc should reduce the (current clamp) peak-to-peak amplitude of spikes. This is not observed in the amputation experiments (Figs. 15 and 16A). Therefore, just passive properties of the dendrite cannot be responsible for the biphasic waveform of the spike.

Amputation ought to have a negative effect on the peak spike current if passive properties of the dendrite are limiting the peak spike current; however, the opposite effect is seen (Fig. 16B). When the amplitudes of both spike phases are plotted against their respective $R_{1}$ values (Fig. 19), the peak spike current is proportional to $1 / R_{1}$ when the hairs are long. In shorter hairs this relationship no longer holds and, thus, other elements than $R_{1}$ limit the peak spike current. It is important to note that the amplitude of the spike does not increase when the hairs are cut down to small stumps. This signifies that the surface area or impedance of the dendrite membrane is not the limiting factor for the peak spike current and is therefore not likely to be a major element of $Z_{s}$. Rees (1968), Thurm (1974), and Thurm and Küppers (1980) all ascribe a high resistance to the dendrite membrane. The finding that the impedance of the dendrite is no limiting factor for peak spike currents does not necessarily contradict these models, as during action potentials the membrane conductance increases considerably (Cole and Curtis, 1939).

To summarize, a retrograde invasion of action potentials into the dendrite cannot be demonstrated and therefore cannot be used to explain the shape of spikes in the olfactory hairs studied here (de Kramer et al., 1984). Consequently, the hypothesis about a longrange electrotonic spread of receptor potential connecting receptor and action potential initiator regions should be reconsidered. The observation that the dendrite contributes to the duration of the positive phase of spikes (Fig. 15) as well as the finding that the impedance of the dendrite does not limit the amplitude of spikes (Figs. 16, $A$ and $b$, and 19) might indicate that the dendrite is actively involved in the generation of the $p_{1}$ phase of spikes. Therefore, it is possible that the action potential is initiated at a dendritic location. In this situation a large scale current loop leading from the receptor to the action potential initiator site, as suggested by Rees (1968), Morita (1963), Morita and Yamashita (1966), Kaissling and Thorson (1980), Thurm (1963, 1970, 1974), Thurm and Küppers (1980),
Wolbarsht (1960), and Wolbarsht and Hanson (1965), is unnecessary. There are additional arguments against this large scale current loop and a somatic action potential initiator site (cf. Maes, 1976). This presumed large scale current loop would have to cross (in our preparation) at least five membranes, the dendrite, apical trichogen outer thecogen, inner thecogen, and soma membrane. The present results show that the apical trichogen and possibly also the thecogen plasma membranes would be serious barriers in such a current loop.

\section{References}

Abrams, T. W., and K. G. Pearson (1982) Effects of temperature on identified central neurons that control jumping in the grasshopper. J. Neurosci. 2: 1538-1553.

Acton, F. S. (1970) Numerical Methods that Work, Harper \& Row, New York Bernard, J., and J. C. Guillet (1972) Changes in the receptor potential under polarizing currents in two insect receptors. J. Insect Physiol. 18: 21732187.

Bernard, J., and J. M. Pinet (1973) Origine des potentiels propagés dans un méchanorecepteur à dendrite longue. J. Comp. Physiol. 87: 361-377

Clausen, C., and N. K. Wills (1981) Impedance analysis in epithelia. In Ion Transport by Epithelia, S. G. Schulz, ed., pp. 79-92, Raven Press, New York.

Clausen, C., T. E. Machen, and J. M. Diamond (1983) Use of AC impedance analysis to study membrane changes related to acid secretion in amphibian gastric mucosa. Biophys. J. 41: 167-178.

Cole, K. S. (1972) Membranes, Ions and Impulses, University of California Press, Berkley.

Cole, K. S., and H. S. Curtis (1939) Electric impedance of the squid giant axon during activity. J. Gen. Physiol. 22: 649-670.

de Kramer, J. J., and J. N. van der Molen (1979) A current clamping amplifier. Med. Biol. Eng. Comput. 17: 407-409.

de Kramer, J. J., and J. N. van der Molen (1980) The pore mechanism of the contact chemoreceptor of the blowfly, Calliphora vicina. In Olfaction and Taste, Vol. VII, H. Van der Starre, ed., pp. 61-64, IRL Press Ltd., London.

de Kramer, J. J., K. E. Kaissling, and T. A. Keil (1984) Passive electrical properties of insect olfactory sensilla may produce the biphasic shape of spikes. Chem. Sens. 8: 289-295.

Elliott, C. J. H. (1983) Wing hair plates in crickets: Physiological characteristics and conncctions with stridulatory motor neurons. J. Exp. Biol. 107: 2147.

Erler, G., and U. Thurm (1981) Dendritic impulse initiation in an epithelial sensory neuron. J. Cornp. Ptiysiol. 142: 237-249.

Freygang, W. H., and K. Frank (1959) Extracellular potentials from single spinal motoneurons. J. Gen. Physiol. 42: 749-760.

Fujishiro N., H. Kijima, and $\mathrm{H}$. Morita (1984) Impulse trequency and action potential amplitude in labellar chemosensory neurons of Drosophila melanogaster. J. Insect Physiol. 30: 317-325.

Gnatzy, W., W. Mohren, and R. A. Steinbrecht (1984) Pheromone receptors of Bombyx mori and Antheraea pernyi. II. Morphometric analysis. Cell Tissue Res. 23.5: 35-42

Grace, A. A., and B. S. Bunney (1983) Intracellular and extracellular electrophysiology of nigral dopaminergic neurons. II. Action potential generating mechanisms and morphological correlates. Neuroscience 10: 317-331.

Guillet, J. C., J. Bernard, J. P. Coillot, and J. S. Callec (1980) Electrical properties of the dendrite in an insect mechanoreceptor: Effects of audidromic or direct electrical stimulation. J. Insect Physiol. 26: 755-762.

Jack, J. J. B., D. Noble, and R. W. Tsien(1975) Electric Current Flow in Excitable Cells, Clarendon Press, Oxford.

Kaissling, K. E. (1974) Sensory transduction in insect olfactory receptors. In Biochemistry of Sensory Functions, L. Jaenecke, ed., pp. 243-273, Springer-Verlag, Berlin.

Kaissling, K. E. (1979) Recognition of pheromones by moths, especially in saturniids and Bombyx mori. In Chemical Ecology: Odor Communication in Animals. F. J. Ritter, ed., pp. 43-56. Elsevier/North Holland Biomedical Press, Amsterdam.

Kaissling, K. E., and J. Thorson (1980) Insect olfactory sensilla: Structural, chemical and electrical aspects of the functional organisation. In Receptors for Neurotransmitters, Hormones and Pheromones in Insects, D. B. Sattelle, L. M. Hall, and J. G. Hildebrand, eds., pp. 261-282, Elsevier/ North I lolland Biochemical Press, Amsterdam.

Katz, B., and R. Miledi (1965) Propagation of electric activity in motor nerve terminals. Proc. R. Lond. Soc. (Biol.) 161: 453-495.

Keil, T. A. (1984a) Reconstruction and morphometry of silkmoth olfactory 
hairs: A comparative study of sensilla trichodea on the antennae of male Antheraea polyphemus and Antheraea pernyi. Zoomorphology 104: 147156.

Keil, T. A. (1984b) Very tight contact of tormogen cell membrane and sensillum cuticle: Ultrastructural basis for high electrical rosistanco between receptorylymph and subcuticular spaces in silk-moth olfactory hairs. Tissue Cell 16: 131-135.

Keil, T. A., and R. A. Steinbrecht (1983) Interrelations of sensory, erveloping and glial cells in epidermal mechano- and chemoreceptors of insects. Verh. Dtsch. Zool. Ges. 76: 294

Kootsley, J. M., and E. A. Johnson (1972) Buffer amplifer with femtofarad input capacity using operational amplifiers. IEEE Trans. Biomed. Eng. 19: 389-391.

Loewenstein, W. R., and Y. Kanno (1964) Studies on an epithelial (gland) cell junction. I. Modifications of surface membrane permeability. J. Cell Biol. 22: 565-586.

Maes, F. W. (1976) Simultaneous chemical and electrical stimulation of labellar taste hairs of the blowfly Calliphora vicina. J. Insect Physiol. 23: 453-460.

Morita, H. (1959) Initiation of spike potentials in contact chemosensory hairs of insects. III. D.C. stimulation and generator potential of labellar chemoreceptor of calliphora. J. Cell. Comp. Physiol. 54: 189-204.

Morita, H. (1963) Generator potential of insect chemoreceptors. Proc. Int Congr. Zool. 3: 105-106

Morita, H., and S. Yamashita (1959) The back firing of impulses in a labellar sensory hair. Mem. Fac. Sci. Kyushu Univ. 4: 83-88.

Morita, H., and S. Yamashita (1966) Further studies on the receptor potential of chemoreceptors in the blowfly. Mem. Fac. Sci. Kyushu Univ. Ser. E 4: $83-93$.

Murray, R. W. (1966) The effect of temperature on the membrane properties of neurons in the visceral ganglion of Aplysia. Comp. Biochem. Physiol. 18: 291-303.

Op de Beek, F. J., F. J. Pasveer, and J. J. de Kramer (1980) Measurement of passive electrical characteristics of taste sensilla. In Olfaction and Taste, Vol. VII, H. Van der Starre, ed., p. 83, IRL Press Ltd., London.

Rauen, H. M. (1964) Biochemisches Taschenbuch, Springer-Verlag, Berlin.
Rees, J. C. (1968) The effect of aqueous solutions of some 1:1 electrolytes on the electrical response of the type 1 ("salt") chemoreceptor cell in the labella of Phormia. J. Insect Physiol. 14: 1331-1364.

Seyfarth, E. A., J. B. Bohnenberger, and J. Thorson (1982) Electrical and mechanical stimulation of a spider slit sensillum. Outward current excites. J. Comp. Physiol. 147: 423-432.

Steinbrecht, R. A., and W. Gnatzy (1984) Pheromone receptors of Bombyx mori and Antheraea pernyi. I. Reconstruction of the organisation of the sensilla trichodea. Cell Tissue Res. 235: 25-34.

Stürckow, B. (1971) Electrical impedance of labellar taste hairs of the blowfly, Caliphora erylhrocephala MG. J. Cormp. Physiol. 72: 131-143.

Terzulo, C. A., and T. Araki (1961) An analysis of intra- versus extracellular potential changes associated with activity of single motorneurons. Ann. N. Y. Acad. Sci. 94: 547-558.

Thurm, U. (1963) Die Beziehungen zwischen mechanischen Reizgrößen und stationären Erregungszuständen bei Borstenfeld-Sensillen von Bienen. J. Comp. Physiol. 46: 351-382.

Thurm, U. (1970) Untersuchungen zur funktionellen Organisation senso* rischer Zellverbände. Verh. Dtsch. Zool. Ges. 63: 79-88.

Thurm, U. (1974) Basics of the generation of receptor potentials in epidermal mechanoreceptors of insects. Abh. Rheinisch-Westfäl. Akad. Wiss. 53: 355-385.

Thurm, U., and J. Küppers (1980) Epithelial physiology of insect sensilla. In Insect Biology in the Future, M. Locke and D. Smith, eds., pp. 735-763, Academic Press, Inc., New York.

Tomita, T. (1956) The nature of action in the lateral eye of the horseshoe crab as revealed by simultaneous intra- and extracellular recording. Jpn. J. Physiol. 6: 327-340.

van Drongelen, W. (1979) Pores in the insect contact-chemoreceptor hair; a theoretical study. Chem. Sens. Flavour 4: 117-126.

Wolbarsht, M. L. (1960) Electrical characteristics of insect mechanoreceptors. J. Gen. Physiol. 44: 105-122.

Wolbarsht, M. L., and F. E. Hanson (1965) Electrical activity in the chemoreceptors of the blowtly. III. Dendritic action potentials. J. Gen. Physiol. 48. 673-683.

Yamada, M. (1971) The dendritic action potentials in an olfactory hair of the fruit-piercing moth Oraesia excavata. J. Insect Physiol. 17: 169-179. 